\title{
ENSURING GLOBALLY THE TANDEM-X HEIGHT ACCURACY: ANALYSIS OF THE REFERENCE DATA SETS ICESAT, SRTM AND KGPS-TRACKS
}

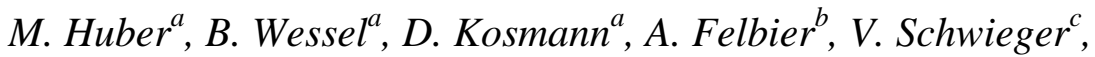 \\ M. Habermeyer ${ }^{a}$, A. Wendleder ${ }^{a}$, A. Roth $^{a}$ \\ ${ }^{a}$ German Aerospace Center, German Remote Sensing Data Center (DLR, DFD), Oberpfaffenhofen,
82234 Wessling, Germany, Email: martin.huber@dlr.de
${ }^{b}$ Technische Universitaet Muenchen (TUM), Remote Sensing Technology, 80333 Munich
${ }^{c}$ Institute for Applications of Geodesy to Engineering (IAGB), University of Stuttgart, 70174 Stuttgart
}

ABSTRACT

The TanDEM-X mission will derive a global digital elevation model (DEM) with satellite SAR interferometry. Height references play an important role to ensure the required height accuracy of $10 \mathrm{~m}$ absolute and $2 \mathrm{~m}$ relative for $90 \%$ of the data. In this paper the main height reference data sets ICESat (for DEM calibration), SRTM (for phase unwrapping) and kinematic GPS-Tracks (KGPS - for DEM verification) are analyzed regarding to their accuracy. For the ICESat data a reliable quality measure is developed. For SRTM an improved version adjusted to reliable ICESat data is presented and a concept for collecting and evaluating decimeter-precise kinematic GPS tracks is proposed.

Index Terms - TanDEM-X, Digital Elevation Model, ICESat, SRTM, kinematic Global Positioning System

\section{INTRODUCTION}

The start of the TanDEM-X (TerraSAR-X add-on for Digital Elevation Measurement) satellite is scheduled for autumn 2009. From then on, it will fly in formation with the very similar TerraSAR-X satellite. This unique constellation will permit the generation of a global elevation model with an accuracy, which was never possible in earlier missions: an absolute height error of $10 \mathrm{~m}$ and a relative height error of $2 \mathrm{~m}$ for $90 \%$ of the data is aimed for (Table I). The horizontal grid will measure 0.4 arc-seconds in longitude, resp. approximately twelve by twelve meters. The absolute horizontal accuracy of 10m (CE90) will be achieved mainly by the precise timing and orbits of the SAR sensors.

TABLE I. TanDEM-X DEM specifications

\begin{tabular}{|c|c|}
\hline Requirement & Accuracy \\
\hline absolute vertical accuracy & $10 \mathrm{~m}$ (LE90) \\
\hline relative vertical accuracy & $2 \mathrm{~m}$ (LE90) (slope $<20 \%)$ \\
$(100 \mathrm{~km} \times 100 \mathrm{~km})$ & $4 \mathrm{~m}$ (LE90) $($ slope $>20 \%)$ \\
\hline
\end{tabular}

Therefore, in this paper the main height reference data ICESat, SRTM and kinematic GPS-Tracks - are analyzed in terms of their accuracy. These height references are used at different stages in the DEM processing to achieve and guarantee the vertical accuracies.

The main absolute height reference for hooking in the interferometric DEMs are ICESat points (DEM calibration). They will ensure that the DEM calibration will reach the $10 \mathrm{~m}$ absolute height error requirement. For this reason it is especially important to develop a reliable quality measure for ICESat data, to ensure to use only ICESat points with an accuracy of some few meters. Comparisons with reference data are therefore carried out to analyze and determine parameters to select the most accurate ICESat points from the data set (chapter 2).

Also, the interferometric SAR processing itself has to be supported by reference heights to fix phase ambiguities. One solution for TanDEM-X is to use SRTM, while another option is to use absolute phase estimation. In addition, height comparisons to SRTM are foreseen to detect phase unwrapping errors. For these tasks, in chapter 3 an improved SRTM version is presented that is fitted towards ICESat heights.

Finally, a global set of kinematic GPS measurements is collected and evaluated with a new evaluation approach to ensure for validation purposes accurate points with less than $1 \mathrm{~m}$ accuracy (chapter 4 ).

All reference data are stored in a data base. An upgrade of this in-house spatial database was necessary to hold and handle point-like data like ICESat and GPS points together with related attributes [1].

\section{QUALITY ASSESEMENT OF ICESAT}

The GLAS instrument (Geoscience Laser Altimeter System) aboard the ICESat (Ice, Cloud, and land Elevation Satellite) measures land elevations since its launch in 2003. Several studies (e.g. [2]) stated a height accuracy of less than $1 \mathrm{~m}$ depending on land cover and relief. The footprint of the 
laser sensor itself has about $70 \mathrm{~m}$ in diameter, spaced at $170 \mathrm{~m}$ intervals in along track. Across track the points are spaced at about $30 \mathrm{~km}$ at the equator getting denser towards higher latitudes (e.g. about $5 \mathrm{~km}$ at $80^{\circ}$ latitude). The good height accuracy, the global distribution and the high number of collected points (over 1 billion by Nov. 2005) make it a valuable reference. Besides the information of latitude, longitude and height each ICESat point also provides a bunch of additional parameters. Unfortunately, many points won't satisfy one-meter accuracy because of clouds, outliers, underlying slopes or vegetation. Therefore, the characteristics of ICESat points were studied in order to extract the most accurate ones serving as GCPs during the DEM calibration and in addition to give a quality level for each ICESat point depending on the parameters.

\subsection{Analysis of parameter}

In the first part of this analysis a comparison between ICESat and different land cover and surface classes is carried out. In the second part parameters are analyzed that characterize accurate ICESat points. As basis for the comparison a digital surface model (DSM) and a digital terrain model (DTM) with a pixel-spacing of $2 \mathrm{~m}$ of the area around the city of Chur, Switzerland is used. As ICESat input the standard "GLAS/ICESat L2 Global Land Surface Altimetry Data (GLA14)” [3] is selected.

To enable easier and faster access to the ICESat data, the provided binary files were imported into the spatial database [1]. During this process annotated flags indicating unreliable measurements were evaluated (e.g. elevation use flag, forward scattering flag), thus reducing the amount of imported data already by 10 -20 percent.

In the first step the differences of ICESat to the elevation models based on the surface types are investigated. The accuracy of the DSM is stated with $\pm 0.5 \mathrm{~m}$ in open areas and $\pm 1.5 \mathrm{~m}$ in areas covered with vegetation. The DTM has an overall accuracy of $\pm 0.5 \mathrm{~m}$. The test-site covers flat and steep terrain as well as bare and vegetated areas. Table II shows that the most accurate points can be found in bare and flat terrain, while solely bare land show a quite larger standard deviation. The forest values show, that the annotated ICESat height lies somewhere inside the vegetation (higher than DTM, lower than DSM).

TABLE II. Accuracy of all ICESat points vs. reference

\begin{tabular}{|l|c|c|c|c|c|}
\hline \multirow{2}{*}{$\begin{array}{l}\text { ICESat- } \\
\text { referenc } \\
\text { e }\end{array}$} & \multicolumn{2}{|c|}{ DTM } & \multicolumn{2}{c|}{ DSM } & \multirow{2}{*}{ \#pts } \\
\cline { 2 - 5 } forest & 6.36 & 6.69 & -5.01 & 6.79 & 277 \\
\hline bare & 1.34 & 4.20 & 0.48 & 3.97 & 74 \\
\hline bare flat & 0.35 & 0.66 & 0.26 & 0.71 & 24 \\
\hline urban & 2.09 & 1.14 & -0.53 & 0.83 & 15 \\
\hline rock & -1.55 & 16.80 & -5.38 & 7.02 & 15 \\
\hline
\end{tabular}

From that entire one can infer, that the focus should be on identifying points in bare and flat areas. Note, that the underlying reference elevation values are weighted with a Gaussian distribution, because the reflected energy of the laser pulse also is reduced towards the edge of the footprint.

In a second step of the analysis ICESat parameters are investigated that may allow to distinguish between different land cover classes. First, the annotated number of peaks is analyzed in order to distinguish between bare land (1-peak assumed) and forest (multiple-peaks assumed). According to our study these assumptions could not be confirmed: the test area contains 9 "1-peak" forest points (vs. 12 "1-peak" bare land) and 30 "6-peak" bare land points (vs. 241 forest). Therefore, the number of peaks can not be solely used as identifier. Anyway, for the final selection in this study 6peak points were removed, to explicitly eliminate most forest points.

As further discriminative ICESat parameters the received energy from signal begin to signal end and the signal width (distance between signal begin and signal end) turned out. For comparison the number of points belonging to the classes bare and bare and flat is further restricted to 'accurate' points that have a difference of less than $1 \mathrm{~m}$ to the reference DTM. The parameter values are compared with the forest points. The Tables III and IV show, that forest points reflect considerably more energy and have a clearly larger signal width than bare/bare and flat points. Hence, the selection process can be supported by applying a threshold to these parameters. To identify points in flat terrain we furthermore use information about the standard deviation of the reference DTM under the ICESat footprint. During the TanDEM Mission the standard deviation will be deduced from the interferometric DEM.

\subsection{Applying selected parameters for ICESat filtering}

Finally, the ICESat data was analyzed with regard to the above mentioned parameters with predefined thresholds:

TABLE III. Parameter 'received energy' in different classes

\begin{tabular}{|c|c|c|c|}
\hline $\begin{array}{c}\text { received } \\
\text { energy } \\
\text { [fJoules] }\end{array}$ & $\begin{array}{c}\text { 'accurate' } \\
\text { bare and flat }\end{array}$ & $\begin{array}{c}\text { 'accurate' } \\
\text { bare }\end{array}$ & 'all' forest \\
\hline mean & 6.21 & 7.96 & 19.76 \\
\hline std & 2.28 & 7.13 & 13.48 \\
\hline \# points & 19 & 42 & 277 \\
\hline
\end{tabular}

TABLE IV. Parameter 'signal width' in different classes

\begin{tabular}{|c|c|c|c|}
\hline $\begin{array}{c}\text { signal width } \\
{[\mathrm{m}]}\end{array}$ & $\begin{array}{c}\text { 'accurate' } \\
\text { bare and flat }\end{array}$ & $\begin{array}{c}\text { 'accurate' } \\
\text { bare }\end{array}$ & 'all' forest \\
\hline mean & 14.12 & 16.42 & 47.95 \\
\hline std & 5.17 & 9.12 & 20.93 \\
\hline \# points & 19 & 42 & 277 \\
\hline
\end{tabular}


TABLE V. ICESat accuracy depending on criteria

\begin{tabular}{|c|c|c|c|c|c|}
\hline $\begin{array}{c}\text { ICESat - } \\
\text { DTM [m] }\end{array}$ & $\begin{array}{c}\text { peaks } \\
<6\end{array}$ & $\begin{array}{c}\text { energy } \\
<10 f J\end{array}$ & $\begin{array}{c}\text { width } \\
<25 \mathrm{~m}\end{array}$ & $\begin{array}{c}\text { std } \\
<7 \mathrm{~m}\end{array}$ & $\begin{array}{c}\text { apply all } \\
\text { criteria }\end{array}$ \\
\hline mean & 1.30 & 2.82 & 0.86 & 3.48 & 0.64 \\
\hline std & 5.61 & 8.23 & 2.82 & 4.99 & 1.30 \\
\hline \# points & 95 & 131 & 100 & 155 & 65 \\
\hline
\end{tabular}

points with less than 6 peaks, received energy lower than 10fJoule, signal width smaller than $25 \mathrm{~m}$ and standard deviation of the underlying DTM less than $7 \mathrm{~m}$. The remaining number of points and their accuracy is listed in Table V. Through combination of the criteria the mean of selected points enhances to $0.64 \mathrm{~m}$ with a standard deviation of $1.30 \mathrm{~m}$, thus providing a set of highly accurate points.

\section{FITTING SRTM TO ICESAT}

To ensure the best available reference DEM for the phase unwrapping process in TanDEM-X the SRTM (C- and Xband) can be improved with the help of ICESat data. According to [4] SRTM is still assumed to have longwavelength errors up to a level of $10 \mathrm{~m}$.

For modeling these long-wavelength errors spherical harmonics are used. The coefficients of the spherical harmonics are estimated by a least-squares adjustment based on the differences between ICESat and SRTM. The previously filtered, reliable ICESat points (cf. chapter 3) are used for the adjustment. The estimation of the coefficients requires globally distributed observations. Thus the earth surface was equally divided into 64800 tiles of $1^{\circ} \mathrm{x} 1^{\circ}$ with a corresponding mean height offset between ICESat and SRTM to reduce the amount of observations. For tiles in the ocean the offsets are set to zero (Figure I). For SRTM CBand offset trends of about $\pm 6 \mathrm{~m}$ are noticeable in southern Africa and north-eastern Europe. The corresponding standard deviations of the differences (Figure II) show large areas with reliable values up to $1.5 \mathrm{~m}$. Relatively high standard deviations are found in the tropical rain forest regions.

One computational limitation is the degree and order to which the spherical harmonics will be expanded. Here a degree and order of 50 was chosen, as tradeoff between computing time and the detail of error description.

By applying a spherical harmonics correction function it is possible to calculate continuously offsets to SRTM, rather than adding only one offset value per tile (Figure III). The results show similar tendencies as stated in [4], while an absolute validation with the GPS-Tracks has still to be done.

\section{GPS-TRACKS FOR VERIFICATION}

For ensuring the final TanDEM-X DEM accuracy after DEM production resp. DEM calibration a verification with higher accuracy reference data is mandatory. These reference data should be available world-wide for larger

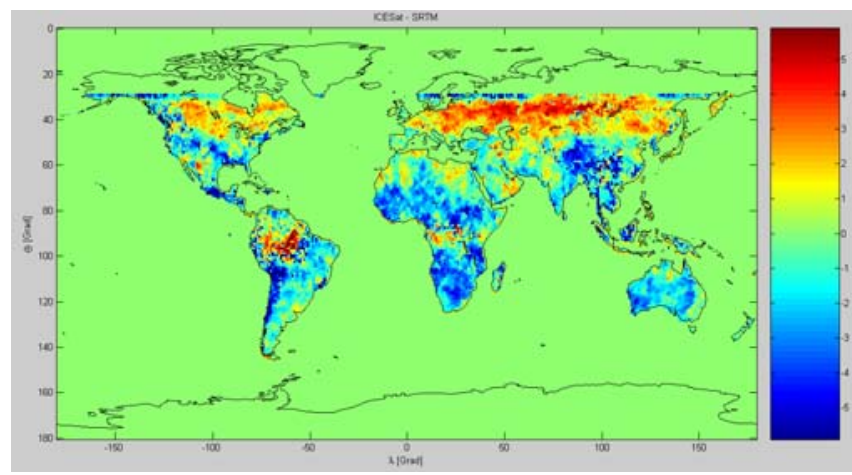

Figure I: Mean differences ICESat-SRTM-C for $1^{\circ} \times 1^{\circ}$ tiles

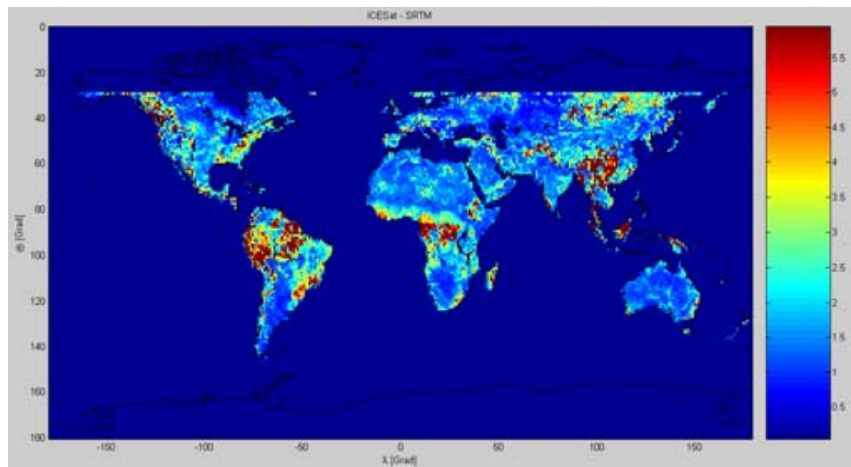

Figure II: Standard deviation of diff. ICESat-SRTM-C

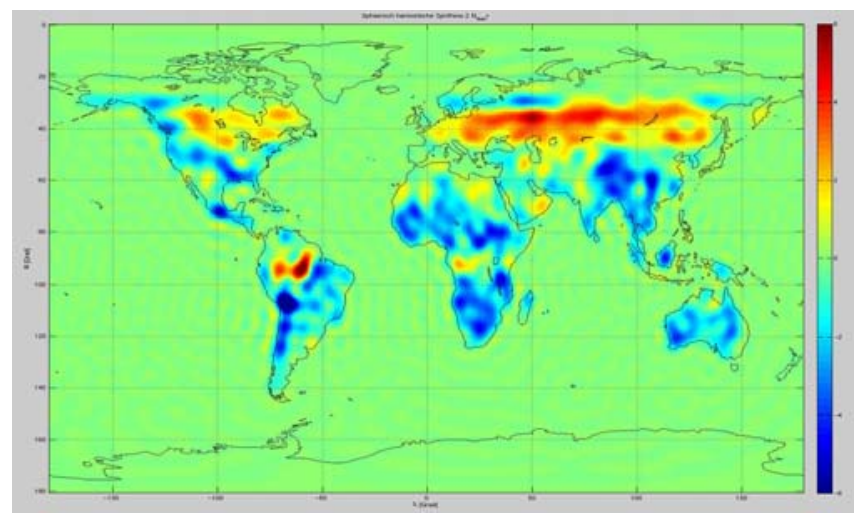

Figure III: Calculated offsets for SRTM-C based on spherical harmonics

regions on each continent. For this purpose GPS tracks with high vertical accuracy better than $50 \mathrm{~cm}$ have to be acquired. For reaching such accuracy the observation of GPS carrier phases is essential. The use of precise differential GPS (PDGPS) using local reference stations is very time-consuming and cost intensive and Continuously Operating Reference Station (CORS) networks are not world-wide available. Therefore a relatively new GPS processing approach, Precise Point Positioning (PPP), has to be used. This approach does not require a GPS reference station network, but precise orbit and time information [5]. Additionally satellite antenna offsets and variations as well as phase wind up corrections have to be considered. Site dependent effects like solid tides and ocean loading effects have to be taken into account as well. 


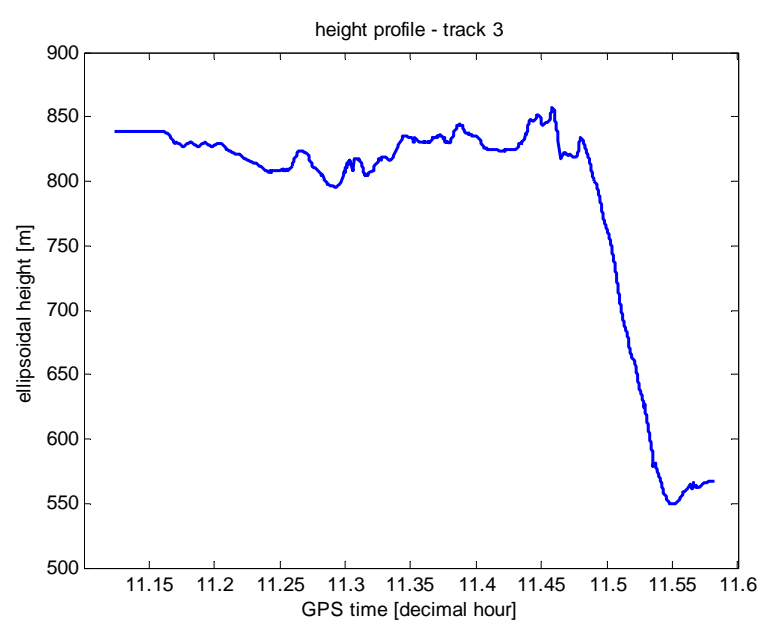

Figure IV Example for an acquired height profile.

Several authors claim that an accuracy of $0.30 \mathrm{~m}$ may be reached without any problems in kinematic mode. This lead to the recommendation to use the phase PPP method for world-wide acquisition of KGPS tracks [6].

The available investigations regarding kinematic phase PPP generally deal with optimal circumstances like e.g. a initialization phase of approximately 30 minutes to get an accuracy below $1 \mathrm{dm}$ [e.g. 6]. Since a time-effective method has to be chosen, the velocity of the acquiring vehicle may be up to $120 \mathrm{~km} / \mathrm{hour}$. This leads to the problem of nonoptimal data with numerous shadowing and multipath effects. Especially the initialisation phase cannot be assured after each signal outage. Signal outages occur very often, e.g. under and behind bridges or behind motorway traffic signs. For this reason some test drives regarding acquisition and evaluation were carried through near Munich, Germany [7].

The PPP post-processing investigations were carried through using IGS final orbits and 30 -seconds clocks. The GIPSY software of JPL was used as primary solution and the PPP online service of "National Resources of Canada" was used for verification. Additionally standard PDGPS results were generated using Leica Geo Office as well as GIPSY again. The PDGPS was evaluated with respect to local reference stations as well as to SAPOS, the CORS network of the German state survey authorities. Figure IV shows the height profile of one of the five test drives.

Finally an accuracy of $0.68 \mathrm{~m}$ could be calculated for PPP solution and the average availability rate of the five test drives was determined between $70 \%$ and $90 \%$. Although the $0.50 \mathrm{~m}$ RMS was not kept the investigations gave the starting shot for the world-wide data acquisition, since a smaller but acceptable availability rate would deliver higher accuracy.

This world-wide acquisition is realized in close cooperation with the FIG (International Federation of Surveyors). Interested scientists and organizations were and are invited to participate in the DEM verification process with KGPStracks. The first results cover a track from Munich, Germany to Sao Martinho, Portugal. Here a newer and more capable GIPSY version was used and the solution was combined with the Natural Resources of Canada Online solution. The final average RMS of the combined solution reached $0.48 \mathrm{~m}$ and the availability rate was calculated to $59 \%$. Both values are in accordance with the defined requirements. Up to now further KGPS tracks are acquired in Europe, South America and China. Plans for Africa, Kazakhstan, North America and Australia are on the way.

\section{CONCLUSIONS}

In this paper an analysis on the reference data sets used for TanDEM-X was made. The preparation of ICESat data, the adaptation of SRTM towards ICESat heights and the evaluation of kinematic GPS tracks was explained.

The TanDEM-X project is partly funded by the German Federal Ministry for Economics and Technology (Förderkennzeichen 50 EE 0601).

\section{REFERENCES}

[1] M. Habermeyer, U. Marschalk, and A. Roth, "Digital elevation model database W42 - A scalable system for spatial data”, 21st ISPRS Congress, 3-11 July 2008, Beijing, China, pp 1253, 2008.

[2] H. Duong, R. Lindbergh, N. Pfeifer, G. Vosselmann, "Icesat full waveform altimetry compared to airborne laser altimetry over the Netherlands", ISPRS Workshop on Laser Scanning 2007 and SilviLaser 2007, 12-14 September 2007, Espoo, Finland, 2007.

[3] H. J. Zwally, R. Schutz, C. Bentley, J. Bufton, T. Herring, J. Minster, J. Spinhirne, R. Thomash, Released: 2006-2008, GLAS/ICESat L2 Global Land Surface Altimetry Data V028, Acquired: 20 February 2003 to 21 March 2008, Boulder, CO: National Snow and Ice Data Center. Digital Media. 2008.

[4] E. Rodriguez, C.S. Morris, J.E. Belz, E.C. Chaplin, J.M. Martin, W. Daffer, S. Hensley, "An assessment of the SRTM topographic products”, Technical Report JPL D-31639, Jet Propulsion Laboratory, Pasadena, California, pp 143, 2005.

[5] P. Héroux, Y. Gao, J. Kouba, F. Lahaye, Y. Mireault, P. Collins, K. Macleod, P. Tétreault, K. Chen, "Products and Applications for Precise Point Positioning - Moving Towards Real-Time”, Proceedings of ION GNSS 2004, Long Beach, CA, pp. 1832-1843, 2004.

[6] K. Ramm, V. Schwieger, "Requirements on Kinematic GPSMeasurements for the Evaluation of Height Accuracy within the TanDEM-X Project”, DLR TanDEM-X Ground Segment Document TD-PGS-TN-3061, 2007.

[7] V. Schwieger, I. Schwieger, "Evaluation of Exemplary Kinematic GPS-Measurements Using Different Methods”, DLR TanDEM-X Ground Segment Document TD-PGS-TN-3097, 2008. 